Article

\title{
Tutorials for Integrating 3D Printing in Engineering Curricula
}

\author{
AMM Sharif Ullah ${ }^{1, *} \mathbb{C}$, Tashi $^{2} \mathbb{D}$, Akihiko Kubo ${ }^{1}$ and Khalifa H. Harib ${ }^{3}$ \\ 1 Faculty of Engineering, Kitami Institute of Technology, Kitami 090-8507, Japan; kuboak@mail.kitami-it.ac.jp \\ 2 Graduate School of Engineering, Kitami Institute of Technology, Kitami 090-8507, Japan; tashi.cst@rub.edu.bt \\ 3 College of Engineering, United Arab Emirates University, Al Ain 15551, UAE; k.harib@uaeu.ac.ae \\ * Correspondence: ullah@mail.kitami-it.ac.jp; Tel./Fax: +81-157-26-9207
}

Received: 19 June 2020; Accepted: 23 July 2020; Published: 27 July 2020

\begin{abstract}
Three-dimensional (3D) printing can revolutionize the way products have been designed and manufactured. This necessitates engineering graduates equipped with the knowledge and skills of 3D printing. As a result, the educational aspects of 3D printing have earned a great deal of attention. Nevertheless, to teach 3D printing in an undergraduate engineering degree program, an outcomes-oriented approach integrating engineering design, object visualization/digitization, and $3 \mathrm{D}$ printing domains can be used. Accordingly, this study presents a tutorial development method to teach undergraduate engineering students the knowledge and skills of 3D printing. The method integrates the abovementioned domains maintaining a hierarchy among the seven ABET-prescribed outcomes. The hierarchy organizes the outcomes into three levels (primary, secondary, and tertiary). The presented method is implemented by introducing a tutorial where a spur gear-pinion pair is designed, visualized, digitized, and 3D printed systematically. E-learning tools can be developed to deliver the tutorial online.
\end{abstract}

Keywords: 3D printing; CAD/CAM; engineering education; tutorial; educational outcomes

\section{Introduction}

Additive manufacturing (AM) [1-3], popularly known as three-dimensional (3D) printing [4,5], has the potential to revolutionize the way products have been designed and manufactured. 3D printing adds materials layer by layer to fabricate an object, unlike subtractive manufacturing (e.g., Computer Numerical Control (CNC) machining) or formative manufacturing (e.g., casting). The material addition processes are classified as binder jetting, directed energy deposition, material extrusion, material jetting, powder bed fusion, sheet lamination, and vat photopolymerization [6]. The benefits of 3D printing are the freedom to design highly customized products, the realization of complex geometry, the fabrication of multi-material objects, and the rapid prototyping $[1,7,8]$. As a result, 3D printing has earned much attention from different sectors including the automotive industry [9], aerospace industry [10], biomedical industry [11], fashion industry [12-14], food industry [15], construction industry [16], and cultural heritage preservation $[17,18]$. This list grows.

A typical workflow of 3D printing is schematically illustrated in Figure 1. As shown in Figure 1, 3D printing is carried out by the following six steps [19]:

(1) Formulate a concept of the object to be fabricated.

(2) Convert the concept into a solid model (virtual model) using off-the-shelf Computer-Aided Design (CAD) packages or other means.

(3) Convert the solid CAD model into a triangulation model (known as STL dataset) that can be read by the relevant $3 \mathrm{D}$ printing system. 
(4) Convert the STL dataset into a set of machine instructions (e.g., G-code) for the layer by layer movements of the printer head(s) for adding materials using the relevant 3D printing system.

(5) Export the machine instructions to a 3D printer and execute the printing process.

(6) Carry out finishing operations (e.g., removing support, polishing, painting, and the like) of the 3D printed object.
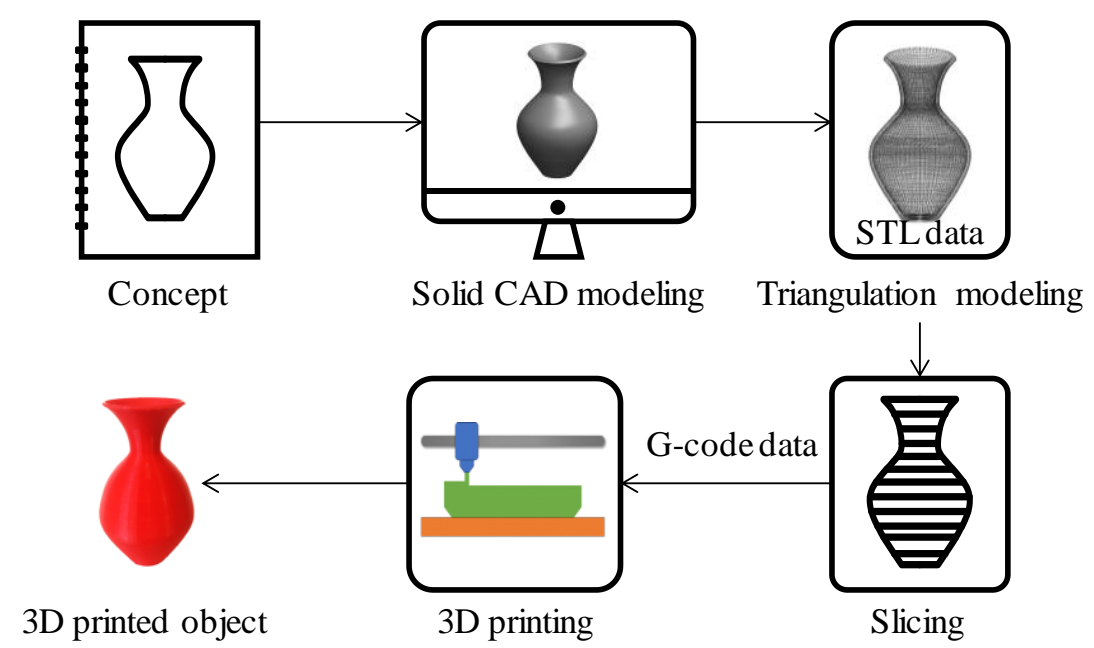

Figure 1. A typical workflow of 3D printing.

As mentioned before, 3D printing can revolutionize the way products have been designed and manufactured [1-18]. This necessitates individuals equipped with the knowledge and skills of 3D printing. Particularly, some engineering students must have the knowledge and skills to implement and improve the workflow regarding 3D printing, as shown in Figure 1. As a result, 3D printing has earned much attention from educators worldwide [20]. An account of the educational aspects of 3D printing is presented in Section 2, showing the educational opportunities and challenges of 3D printing in engineering and other fields (e.g., medicine). However, as far as the quality of engineering education is concerned, a set of prescribed outcomes must be considered while developing course contents, delivering them, assessing students, and reporting the quality of education [21]. (Section 3 deals with outcome-oriented educational activities.) As such, the educational activities of 3D printing must follow an outcome-oriented approach (see Section 3) as explicitly as possible for engineering students. At the same time, the approach must integrate engineering design domain, object visualization/digitization domain, and 3D printing domain. (These domains are described in Section 3). As a result, a tutorial that integrates the abovementioned domains with the aid of some predefined educational outcomes can seamlessly integrate 3D printing in engineering curricula. Accordingly, this article's objective is to develop an outcome-oriented approach that can educate students with the knowledge and skills of 3D printing, integrating engineering design, object visualization/digitization, and 3D printing domain. The structure of this article is as follows. Section 2 describes the relevant research work available in the literature regarding the educational aspects of 3D printing. Section 3 presents a method to develop outcomes-oriented tutorials for incorporating 3D printing in engineering curricula. Section 4 presents a case study showing one of the tutorials developed based on the proposed method. Section 5 concludes this article.

\section{Related Work}

As mentioned before, 3D printing has earned much attention from educators worldwide [20]. Many authors have reported 3D printing's contributions in education, including its effectiveness, advantages, limitations, and avenues for improvement [22]. For the sake of better understanding, this section briefly describes some of the related work as follows. 
Many authors have studied the general aspects of 3D printing in education. For example, Chekurov et al. [23] reported 3D printing's effectiveness in enhancing engineering students' creativity. This numerical study also showed that the contents relevant to design for 3D printing help students enhance their creativity if the contents are offered in multiple years. Diriba et al. [24] studied the maturity timeline of 3D printing technology and elucidated its social, ethical, and legal challenges. In particular, the authors showed that 3D printing is useful in achieving "educate to innovate." Furthermore, the authors emphasized that higher education institutes should take the lead regarding the 3D printing-based collaborations using university-industry-government relationships. This necessitates 3D printing-related education at all levels. Despeisse and Minshall [25] used a literature review and evidence collected from workshops to identify the key educational themes by which the current skill gap and barriers in implementing 3D printing can be addressed.

Many authors have studied the educational aspects of 3D printing targeted at high school and undergraduate students and instructors. For example, Kirchheim et al. [26] described tutorials to teach 3D printing to undergraduate students and lifelong learners from product development and other relevant issues (e.g., quality control). They showed that knowledge and skills of realizing relatively complex parts using 3D printing enhance learners' open-ended problem-solving capability. Urbanic [27] presented some 3D-printing-based undergraduate design projects to impart the knowledge and skills of the real-life design process to the students. The author showed that the students could successfully fulfill the desired engineering requirements without using highly technical knowledge. Fidan et al. [28] reported the effectiveness of Additive Manufacturing Studios in engineering education. The target is the K-12 and community college teachers and students where several institutes and a larger number of instructors collaborate. Through the Additive Manufacturing Studios, the instructors grasp the meaning of student outcomes prescribed by ABET, in addition to the current trend of these technologies.

Many authors have studied the educational aspects of 3D printing in science, technology, engineering, and mathematics (STEM). For example, Ali and Khine [29] compiled twelve selected articles dealing with the current trends and theoretical and practical aspects of $3 \mathrm{D}$ printing in teaching and learning of STEM. For another example, consider the article by Alhamad et al. [30]. In this article, the authors reported that 3D printed objects (e.g., car, truck, aero-foils, and wings) help engage students more intensely in learning advanced engineering topics (e.g., fluid mechanics, mechanics of materials, and alike). Asiabanpour [31] showed the effectiveness of additive manufacturing in engineering education. The author designed a stand-alone additive manufacturing course and discussed various examples wherein AM had been utilized as a service and outreach tool to recruit $\mathrm{K}-16$ students into STEM programs. Lin et al. [32] studied the effects of 3D printing on the development of high school students' knowledge structures toward the engineering design process. This quasi-empirical study showed that 3D printing, coupled with modeling principles, could help students elaborate on modeling and feasibility analysis concepts. Whether or not 3D printing can help when the students are exposed to multiple modeling tasks is still a research question [32].

Many authors have studied the educational aspects of 3D printing targeted at eLearning, CAD/CAM (CAM stands for Computer-Aided Manufacturing), and product development. For example, Loy [33] studied 3D printing to empower eLearning. The author showed examples of how the students integrated the virtual and real worlds from the context of eMarking. Galina and Na [34] showed that making 3D printing facilities available to a library space helps many students transform theory into a physical reality, and, thereby, learn the relevant subject matter more effectively. Other studies (e.g., [35]) also support similar findings. Verner and Merksamer [36] implemented the learning concept called conceive-design-implement-operate, integrating 3D printing facility with parametric CAD package and equation editor. As reported by the authors, a wide range of engineering students could enhance their engineering competencies through this 3D-printing-based learning approach. Liu and Jin [37] developed a detailed digital manufacturing course framework for senior aircraft manufacturing engineering undergraduates. According to this framework, 3D-printing-related 
content, along with traditional CAD-CAM-CAE (CAE stands for Computer-Aided Engineering)and digital-metrology-related content, must be incorporated to educate individuals who want to pursue a career in the aircraft manufacturing industry.

Medical students often learn about human structures and apply the relevant knowledge in clinical contexts throughout their study periods. They need to communicate what they have learned regarding human structures and clinical/surgical diagnosis to the stakeholders (their peers, educators, and patients). 3D printing nowadays plays a vital role in the abovementioned educational and learning aspects. Many authors have studied the implementation of 3D printing in medical education. For example, Ransikabum et al. [38] reported a feasibility study on the fabrication of a 3D medical model aiming to enhance medical students' learning. The study reported a six-step process of additive manufacturing that links additive manufacturing to medical imaging for understanding. This kind of education can be delivered effectively if 3D printing is integrated with medical education, as reported by many authors [39-44]. Apart from 3D printing's contributions to mainstream STEM and medical education, as mentioned above, it is equally beneficial to educating individuals with special needs [45].

\section{Tutorial Development Method}

This section presents a general method to develop tutorials for educating undergraduate engineering students with the knowledge and skills of 3D printing. Before introducing the method, some salient points are described below, which are complementary to the educational issues described in the previous section.

\subsection{Outcome-Oriented Depth-Breadth-Based Engineering Education}

The objective of engineering education is to produce "T-shaped" engineers equipped with a breadth of knowledge and depth of expertise [46]. Engineering design is one way to nurture the students' breadth of knowledge and depth of expertise. In engineering design courses, students apply the knowledge gained to design and build systems/devices; the designed systems/devices must meet the predefined standards and multiple constraints [47]. However, there are many proximal stakeholders in the ecosystem of engineering education: students, instructors, institutes, professional societies, employers, and accreditation bodies [46]. An outcome-oriented approach makes a curriculum transparent and accountable to the stakeholders $[47,48]$, requiring some learning outcomes, as mentioned before. The set of outcomes has been evolving [47]. Currently, seven outcomes as listed in Table 1 are followed by ABET-accredited engineering programs $[47,48]$.

Table 1. ABET Educational Outcomes for Undergraduate Engineering Programs $[47,48]$.

\begin{tabular}{cl}
\hline Outcomes & \multicolumn{1}{c}{ Descriptions } \\
\hline 1 & $\begin{array}{l}\text { Students can apply engineering, science, and mathematics knowledge to identify, formulate, } \\
\text { and solve problems }\end{array}$ \\
\hline 2 & $\begin{array}{l}\text { Students can produce solutions executing the processes of engineering design to meet specified } \\
\text { needs relevant to public health, safety, and welfare, as well as global, cultural, social, } \\
\text { environmental, and economic factors }\end{array}$ \\
\hline 3 & $\begin{array}{l}\text { Students can communicate effectively with a wide range of audiences using oral, written, and } \\
\text { digital means }\end{array}$ \\
\hline 5 & $\begin{array}{l}\text { Students can make informed judgment considering the impact of engineering solutions in global, } \\
\text { economic, environmental, and societal contexts as a response to their ethical and professional } \\
\text { responsibilities }\end{array}$ \\
\hline 7 & $\begin{array}{l}\text { Students can establish goals, plan tasks, and meet objectives being members of a collaborative } \\
\text { and inclusive team with shared leadership }\end{array}$ \\
\hline 6 & $\begin{array}{l}\text { Students can develop and conduct appropriate experimentation, analyze and interpret data, and } \\
\text { use engineering judgment to conclude }\end{array}$ \\
\hline
\end{tabular}


The first outcome ensures that the students can apply engineering, science, and mathematics knowledge to identify, formulate, and solve problems. The second outcome ensures that the students can produce solutions executing the processes of engineering design to meet specified needs relevant to public health, safety, welfare, as well as global, cultural, social, environmental, and economic factors. The third outcome ensures that the students can communicate effectively with a wide range of audiences using oral, written, and digital means. The fourth outcome ensures that the students can make informed judgment considering the impact of engineering solutions in global, economic, environmental, and societal contexts as a response to their ethical and professional responsibilities. The fifth outcome ensures that the students can establish goals, plan tasks, and meet objectives being members of a collaborative and inclusive team with shared leadership. The sixth outcome ensures that the students can develop and conduct appropriate experimentation, analyze and interpret data, and use engineering judgment to conclude. The last outcome ensures that the students can acquire and apply new knowledge as needed, using appropriate learning strategies.

\subsection{Method}

Thus, how to uphold the abovementioned seven outcomes while educating students with engineering design is an important aspect of engineering education. In this respect, a 3D printer can play a vital role. Based on this consideration, a tutorial development method is proposed, as schematically illustrated in Figure 2. The proposed method integrates the abovementioned seven educational outcomes and the following three domains: (1) engineering domain, (2) object visualizing and digitization domain, and (3) 3D printing domain. The tasks performed in the engineering domain ensure that the object (to be) realized is modeled so that the results can be handled in the next domain. The tasks performed in the object visualizing and digitization domain help visualize the object for the sake of human understanding and digitize it for 3D printing. The tasks performed in the last domain ensure that the object is printed using an available 3D printer. In the proposed method, any set of outcomes out of the seven can be associated with the domain-specific tasks. This results in many different tutorials (Tutorial $1, \ldots$, Tutorial $i, \ldots$ ), as schematically illustrated in Figure 2. This implies that in the tutorial domains an instructor chooses some of the outcomes while developing a tutorial. Moreover, there is a hierarchy that must be maintained among the outcomes and domains. This leads to a task-outcome hierarchy diagram. One of the possible hierarchies is shown in Figure 3. As seen in Figure 3, some of the outcomes are directly related to the task domains. These are defined as primary outcomes. Some of the outcomes are directly related to the primary outcomes. These are defined as secondary outcomes. Lastly, some of the outcomes are related to all task domains, as well as to the primary and secondary outcomes in a concurrent manner. These outcomes are defined as tertiary outcomes. On the other hand, in the task domains, there are six processes, denoted as A, B, C, D, E, and $\mathrm{F}$. The processes $\mathrm{A}, \mathrm{C}$, and $\mathrm{E}$ are the outcomes of the activities associated with the engineering, object visualizing and digitization, and 3D printing domains, respectively. The processes $\mathrm{B}, \mathrm{D}$, and $\mathrm{F}$ are the outcomes of the activities that link the respective domains. The activities in processes $\mathrm{B}$ and $\mathrm{F}$ link the engineering domain to the other two domains, respectively, whereas process D links the object visualizing and digitization domain to the $3 \mathrm{D}$ printing domain. 


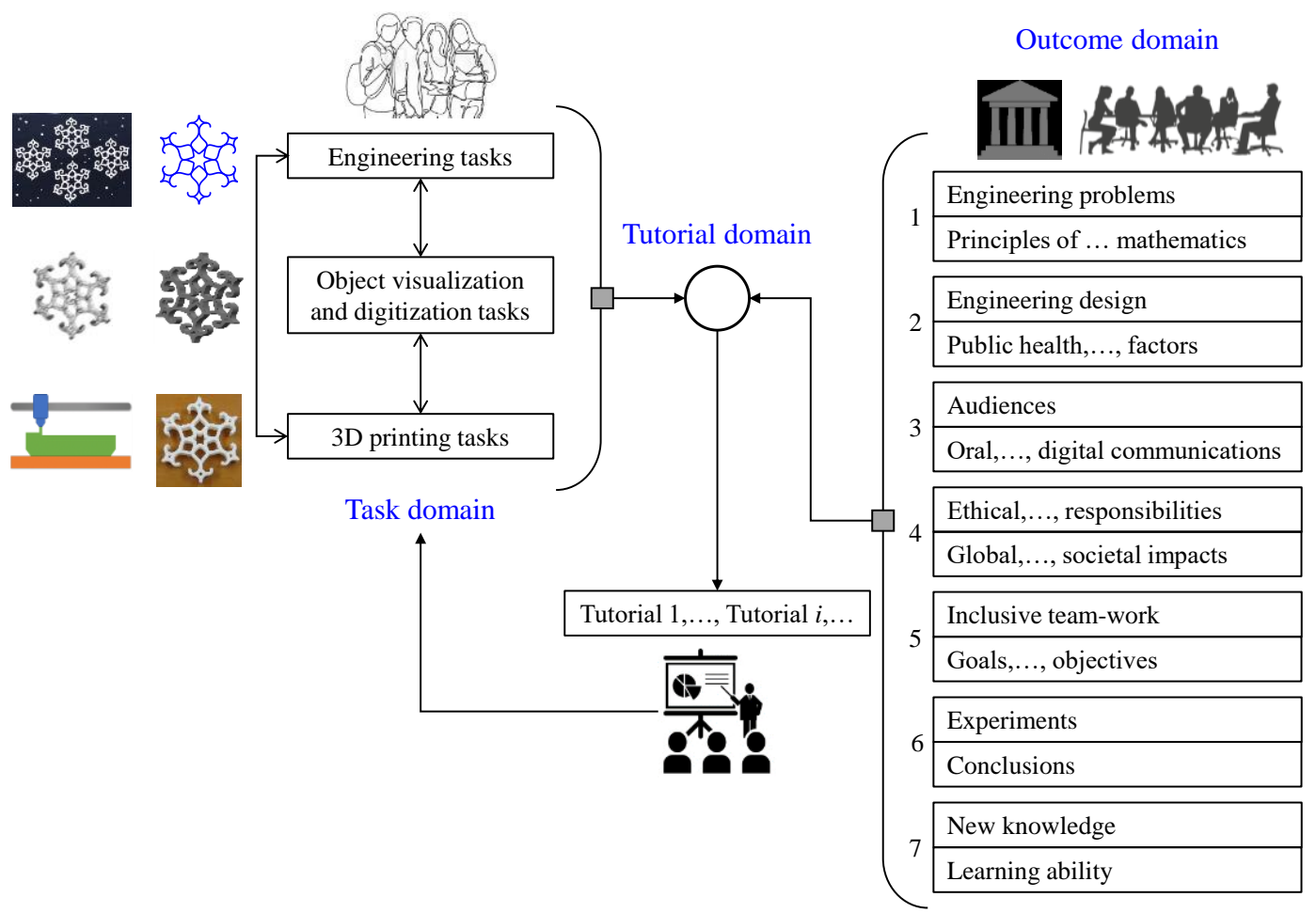

Figure 2. Tutorial development method.

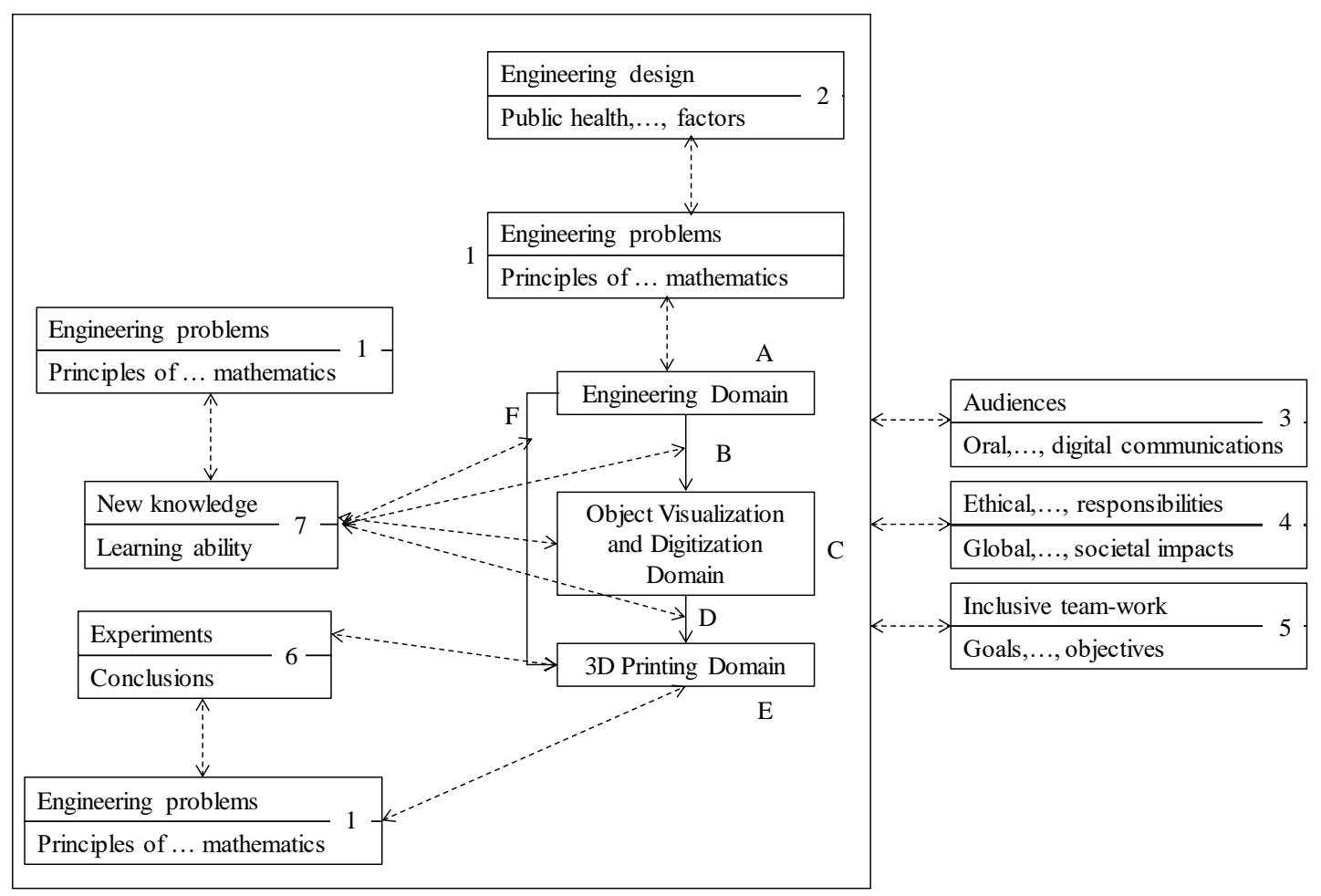

Figure 3. A hierarchy among outcomes and task domains.

As seen in Figure 3, the process denoted as A is directly linked to Outcome 1, and Outcome 1 is directly linked to Outcome 2. Thus, the activities associated with A mean that the students apply the knowledge of engineering, science, and mathematics to identify, formulate, and solve a given problem. Subsequently, the students consider some real-life constraints and coordinate the tasks associated with Outcome 1 to formulate a design process. As such, Outcome 2 becomes a secondary outcome of A. 
For example, if the given problem is to materialize an aerofoil, the students apply a set of governing equations in determining its shape. Subsequently, the students define the aerofoil design process considering some real-life constraints (e.g., aerofoil for a small aircraft). Now, B is directly linked to Outcome 7 and makes A meaningful to the next domain (object visualizing and digitization domain). Thus, the students acquire and apply knowledge to create the shape information of aerofoil in such a way so that the information can be handled in C. Acquiring new knowledge is again linked to Outcome 1 ; that is, the students must apply some other pieces of mathematical, engineering, and scientific knowledge other than the governing equations of the aerofoil. $\mathrm{C}$ is also directly linked to Outcome 7 and indirectly linked to Outcome 1. As a result, in this case, students acquire knowledge to create a 3D solid model of the object (aerofoil) using the information acquired from the process B. In this case, a default choice is to use an off-the-shelf CAD package. As such, the students learn from other sources (that goes beyond the course where this tutorial is integrated) how to transfer the aerofoil's shape information to CAD software. Once the activities associated with $C$ are done, it is time to perform the activities associated with D. Since most of the 3D printing systems can work on the triangulated dataset of the objective to be fabricated (STL dataset [49]), D entails the activities that ensure that the triangulated dataset of the object is prepared based on a predefined standard. This can be done using the functions offered by the CAD software. However, a full understanding requires the knowledge of an entity called a facet. A facet captures the information of a triangle in the triangulated model of an object. The information is as follows: (1) the three vertices of a triangle, (2) the order of the vertices, and (3) one of the normal vectors of the tringle showing its orientation (outward of the object to be fabricated).

Thus, D associates Outcome 7 (the ability of self-learning from reference materials of given CAD software), and, at the same time, Outcome 7 associates Outcome 1 (triangulation related vector algebra). Alternatively, if the students produce the necessary triangulation dataset directly in the engineering domain by developing a dedicated program or some other means, it can be transferred to the 3D printing domain for performing the tasks related to $E$. These alternative paths related activities constitute F. Thus, $\mathrm{F}$ is also directly related to Outcome 7. In addition, Outcome 7 is associated with Outcome 1, similar to D. Since E refers to all activities associated with 3D printing in the 3D printing domain, it can be oriented toward achieving Outcome 6 and Outcome 1. When Objective 6 is emphasized, the students are supposed to carry out an experiment, analyze and interpret data, and draw conclusions. In the case of 3D printing, the students can fabricate the object several times varying the printing conditions (layer thickness, feed rate, filling rate, and alike) and printing methods (e.g., stereolithography, fused deposition, and alike) and measure the accuracy of the fabricated object. The students may use data analysis knowledge and optimize the printing process using some realistic criteria (minimize energy and material consumptions, maximize accuracy, and like). Thus, Outcome 6 is concurrently related to Outcome 1 . On the other hand, students may be assigned to develop an analytical or empirical model of the 3D printing process. If it is done, then the $3 \mathrm{D}$ printing domain directly relates Outcome 1, as schematically illustrated in Figure 3. When the students achieve the primary and secondary outcomes (Outcomes 1, 6, and 7), as schematically illustrated in Figure 3, the tertiary outcomes can simultaneously be achieved. For example, if the students can articulate the ethical issues (e.g., positive social changes that they can bring about using the competency they have gained through performing the tasks associated with A, .. , F), then the tertiary outcome, Outcome 4, is covered. If the students form a team with shared responsibilities and perform accordingly, then the tertiary outcome, Outcome 5 , is covered. If the students prepare a detailed report on how they have conducted A, ... F being, at the same time, aware of the outcomes (Outcomes 1, . , 7), then the tertiary outcome, Outcome 3 , is covered. Now, it may not be easy to articulate the new knowledge gained (Outcome 7). In this respect, the knowledge taxonomies [50,51] can be used. 


\section{Implementation}

The previous section presents a general method to develop tutorials for educating undergraduate engineering students with the knowledge and skills of 3D printing. This section implements the method by eliciting a tutorial. In particular, the tutorial deals with 3D printing of a spur gear. Thus, it is suitable for senior-level undergraduate students enrolled in mechanical, industrial, and manufacturing degree programs. The descriptions of the tutorial are as follows.

\subsection{Outline of the Proposed Tutorial}

Most of the students enrolled in the undergraduate mechanical, industrial, and manufacturing degree programs learn about machine elements (gear, pulley, shaft, bolts, and alike). They are familiar with the governing equations of the elements and their usages in electromechanical systems. They might be familiar with building a solid model of a spur gear using an off-the-shelf CAD package. Based on this consideration, Figure 4 schematically illustrates the structure of the tutorial.

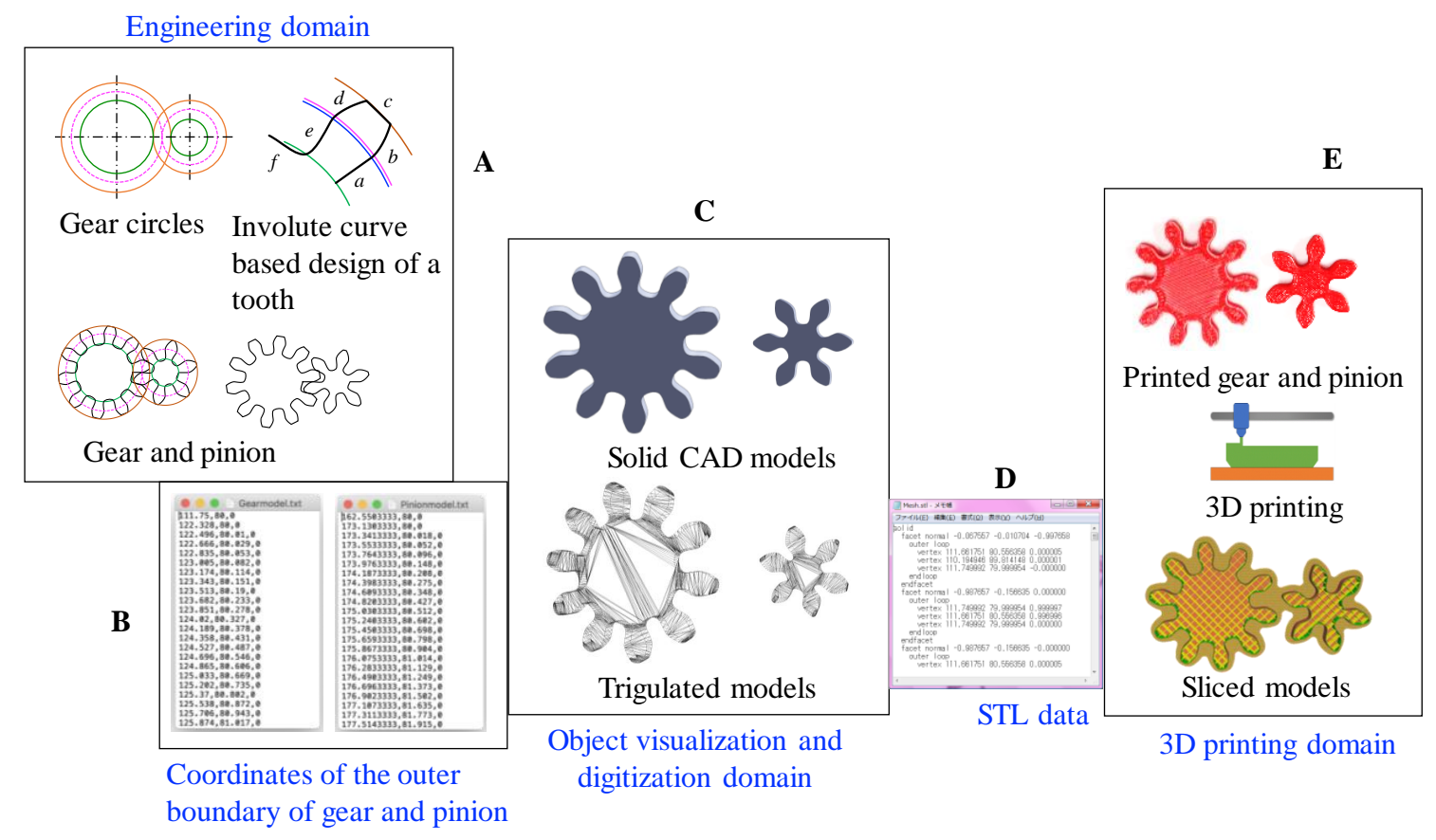

Figure 4. A tutorial for 3D printing in education.

As seen in Figure 4, the tutorial consists of processes denoted as A, .. , E; F is not included in this tutorial. A (engineering domain) deals with how to design a spur gear. B deals with the dataset consisting of the coordinates of the outer boundary of the designed gear-pinion pair. C (object visualization and digitization domain) deals with solid modeling of spur gear-pinion pair with the aid of off-the-shelf CAD software. B's input is the set of coordinates of the outer boundary of the designed gear/pinion. D deals with STL data [49] preparation from the triangulated model of the gear/pinion. E (3D printing domain) deals with 3D printing of the gear-pinion pair using an ordinary 3D printer.

\subsection{Administering the Tutorial}

To administer $\mathrm{A}$, the instructor can assign students to determine the governing equations of a tooth of a spur gear. The instructor can assign students to formulate a tooth model consisting of six segments $(a, \ldots, f$ as shown in Figure 4$)$ within the realm of the four circles known as pitch, base, outer, and root circles. Out of these segments, the segments $b$ and $d$ are the involute curves [52]. Others are the lines connecting $b$ and $d$ to the abovementioned circles. If the students can perform the above assignment, they fulfill the primary outcome (Outcome 1). 
Afterward, the students can consider the engineering design aspect, which refers to a secondary outcome (Outcome 2). As such, the students can apply a system approach-input processing-output approach. In the input module, the students can ask a gear designer to input the values of velocity ratio, number of teeth of the gear, number of teeth of the pinion, pressure angle, and diametric pitch. In the processing module, all sorts of calculations can be performed to determine the distance between the centers of gear and pinion; dimensions of the addendum and dedendum; values of clearance and contact ratio; dimensions of the pitch, base, outer, and root circles of gear/pinion; values of working depth; tooth thickness; and rotation angle of gear/pinion [52]. In the output module, the designed gear-pinion pair can be visualized.

Figure 5 shows the screen-print of a spreadsheet-based gear design tool. If the students can build a similar design tool, they fulfill both primary and secondary outcomes (Outcomes 1 and 2). Therefore, the instructor can evaluate students based on whether they can build a design tool similar to the one shown in Figure 5.

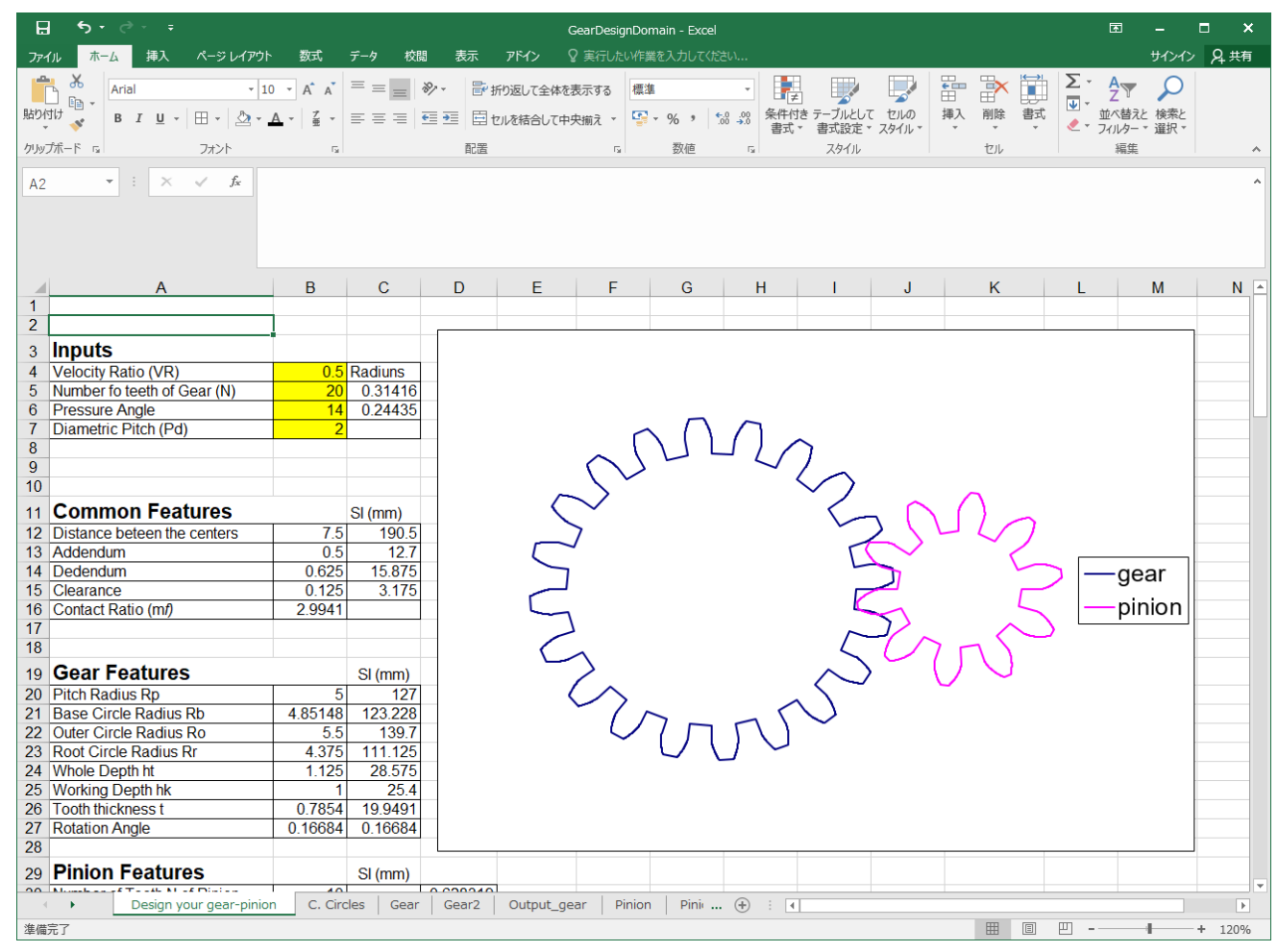

Figure 5. A tool for designing spur gear.

In $B$, the instructor can assign students to extract the design information of gear/pinion in terms of some points because most of the off-the-shelf CAD packages nowadays have a function to input coordinates of points collected from an external source. Thus, the students must go through the manual of the given CAD package and make sure of the underlying data format. This means that the students' self-learn how the coordinate data input function works for the given CAD package. As a result, Outcome 7 becomes the primary outcome of B. On the other hand, Outcome 1 becomes the secondary outcome because the students must apply the knowledge of parametric curves to parameterize the equations of gear/pinion segments $(a, \ldots, f)$ for representing the segments using some points. At the same time, the students must apply basic geometric modeling techniques (e.g., rotation of point/curve centering a point/axis). Therefore, the instructor monitors and evaluates the students' performance based on Outcome 7 (primary outcome) and Outcome 1 (secondary outcome). If successful, the students produce documentation similar to the one shown in Figure 6. As seen in Figure 6, the students plot the 
coordinates of the gear and pinion's outer boundaries and store them in text files (ASCII) so that the information becomes meaningful to the tasks underlying $C$.

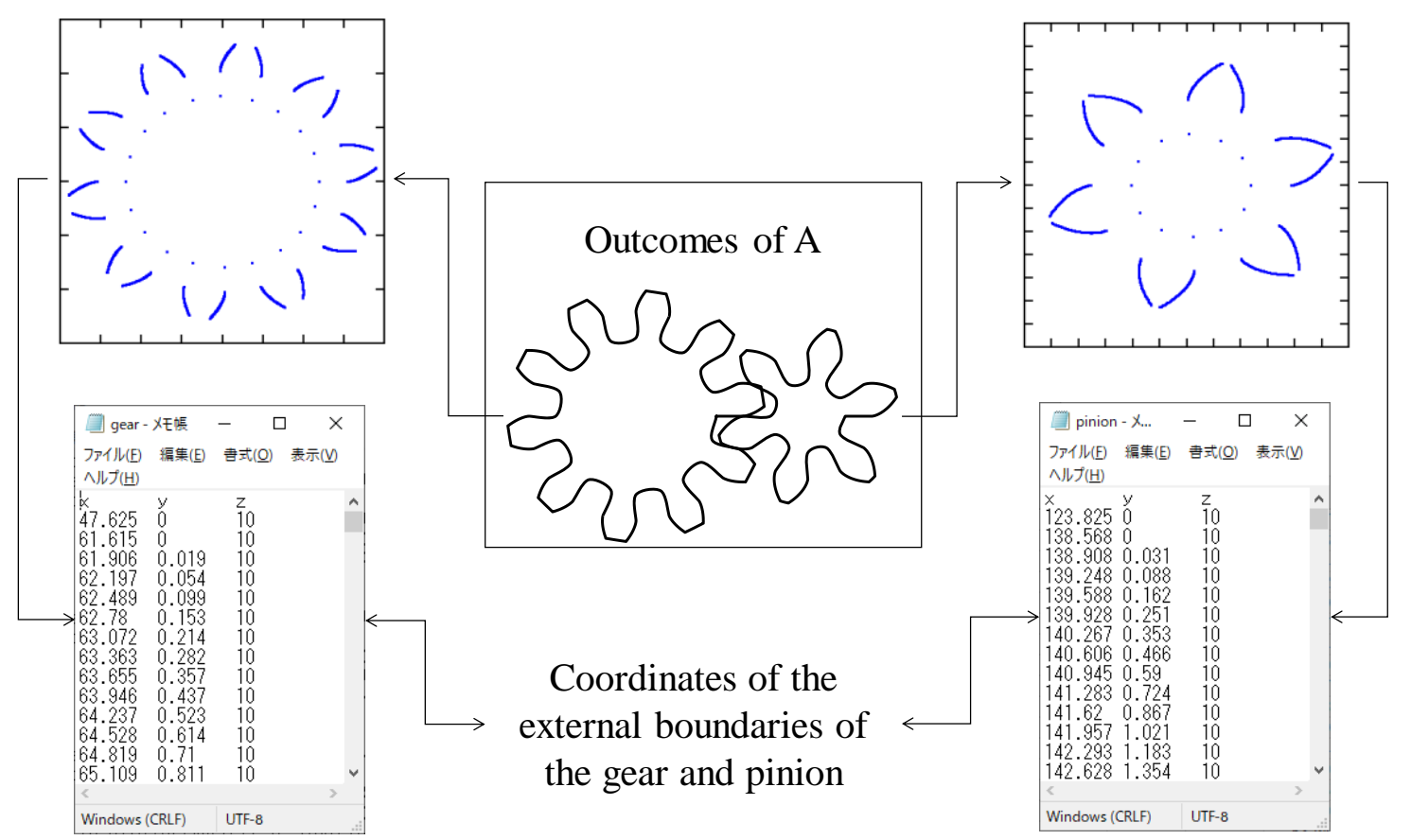

Figure 6. Outcomes of B with respect to those of A.

In $C$ (object visualization and digitization domain), the gear/pinion coordinate information generated in B (the text files are shown in Figure 6) is used to create a solid model of gear/pinion. In this respect, the students need to know how a set of points stored in an ASCII text file can be input into the given CAD package. The students also find out the required operations to perform constructive solid modeling [53]. The students self-learn how the CAD package converts points to a curve, and then a solid model. Therefore, Outcome 7 becomes the primary outcome of $C$. At the same time, the students must apply the knowledge of geometric modeling to triangulate all faces in the solid model of the gear/pinion. The triangulation process stores the gear/pinion in terms of facets where a facet means three vertices of a triangle and a normal vector defining the orientation of the triangle. Thus, Outcome 1 becomes a secondary outcome of $C$. If successful, the students produce documentation similar to the one shown in Figure 7. As seen in Figure 7, the students produce the solid models and triangulate models of the gear and pinion, respectively using the output of B. Thus, the instructor assesses the students' performance based on the contents shown in Figure 7, keeping in mind that Outcomes 7 and 1 are the primary and secondary outcomes, respectively.

In D (STL data domain), the students are required to create the STL [49] datasets of gear and pinion. Most of the off-the-shelf CAD packages have the function to generate STL data from a solid model. Thus, the students need to know how to create an ASCII text file that stores the STL data using a given CAD package. This means that the students self-learn how the CAD package converts a triangulated model into STL data format. Therefore, Outcome 7 becomes the primary outcome of D. At the same time, the students must know the construction of an STL data block. An STL data block consists of three vertices and a normal vector, and the information of these four elements must be stored in a specific format [49]. This requires the knowledge of calculating the normal vector from three vertices of a triangle [54]. Thus, Outcome 1 becomes a secondary outcome of D. If successful, the students produce documentation similar to the one shown in Figure 8. As seen in Figure 8, the students produce two text files (ASCII format) storing the STL datasets of the designed gear and pinion. Thus, the instructor assesses the students' performance based on the contents shown in Figure 8 (only the segment marked D), keeping in mind that Outcomes 7 and 1 are the primary and secondary outcomes, respectively. 


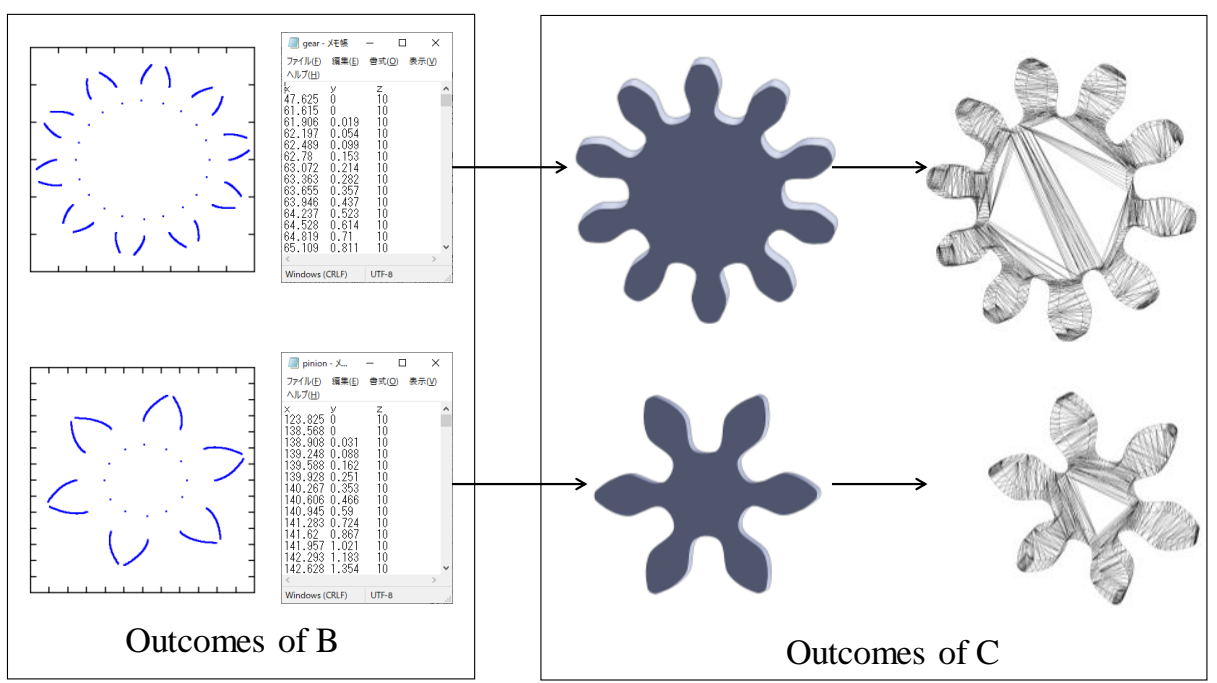

Figure 7. Outcomes of $\mathrm{C}$ with respect to those of $\mathrm{B}$.

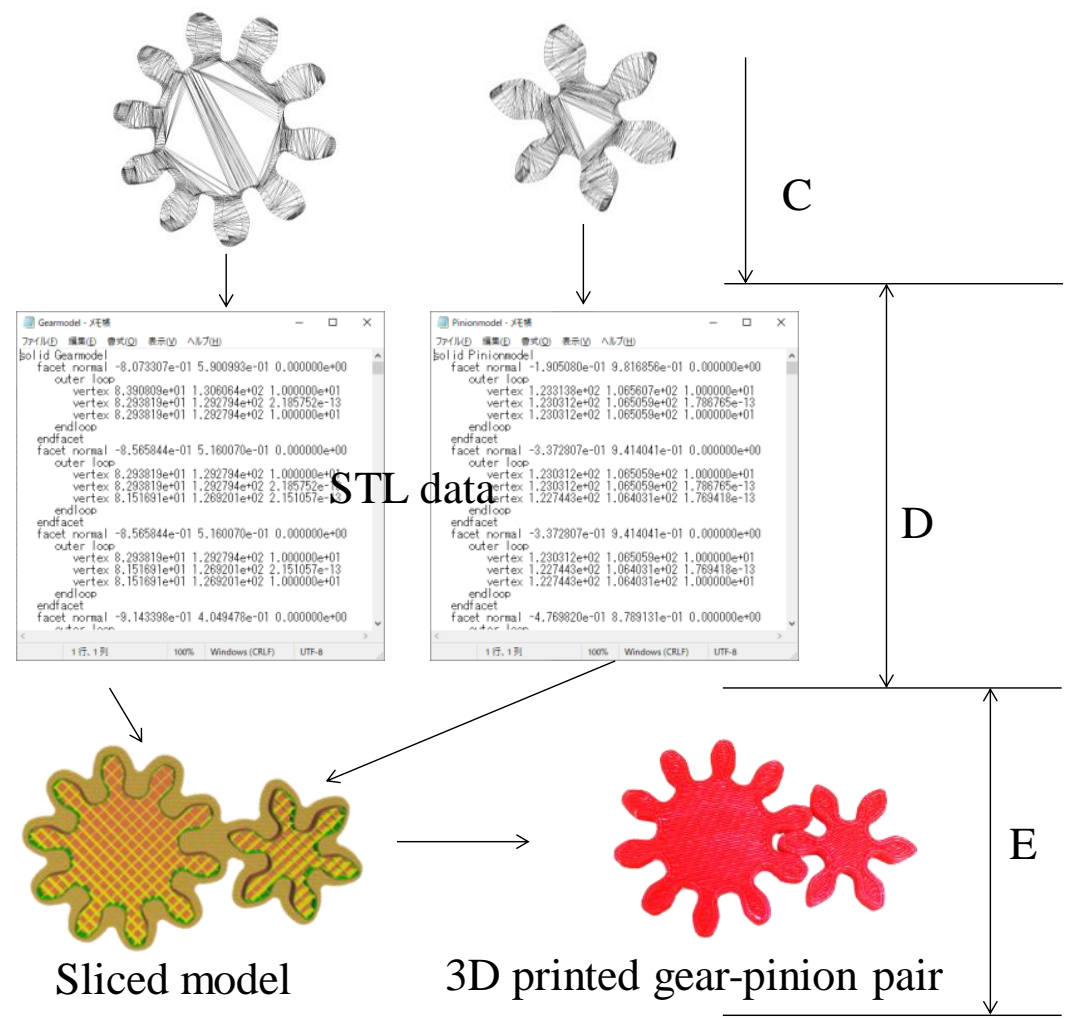

Figure 8. Outcomes of D and E with respect to C.

In $\mathrm{E}$ (3D printing domain), the students are required to print the gear and pinion using a given (most likely a commercially available) 3D printer. Thus, the instructor assesses the students' performance based on the contents shown in Figure 8 (only the segment marked E). In this case, the instructor uses Outcome 6 as the primary outcome and Outcome 1 as the secondary outcome. As a result, the instructor must instruct the students to print the same object (in this case, a gear-pinion pair) several times by changing the printing conditions (filling rate, printing head feed rate, layer thickness, and alike) and to measure the printing performance (e.g., printing time, the material used, energy consumption, accuracy/precision of the gear and pinion, shape error, surface roughness, and alike). The students can interpret in terms of quality, sustainability [55], and alike using relevant analytical knowledge 
(Outcome 1). Figure 9 shows some of the examples of gear and pinion pairs that the students printed. Based on the students' preferences, the size and shapes of the gears and pinions are different. A group of students has taken a video clip demonstrating that the gear-pinion pair has been printed according to the design because they rotate very smoothly. Refer to the Supplementary materials to run the video clip.

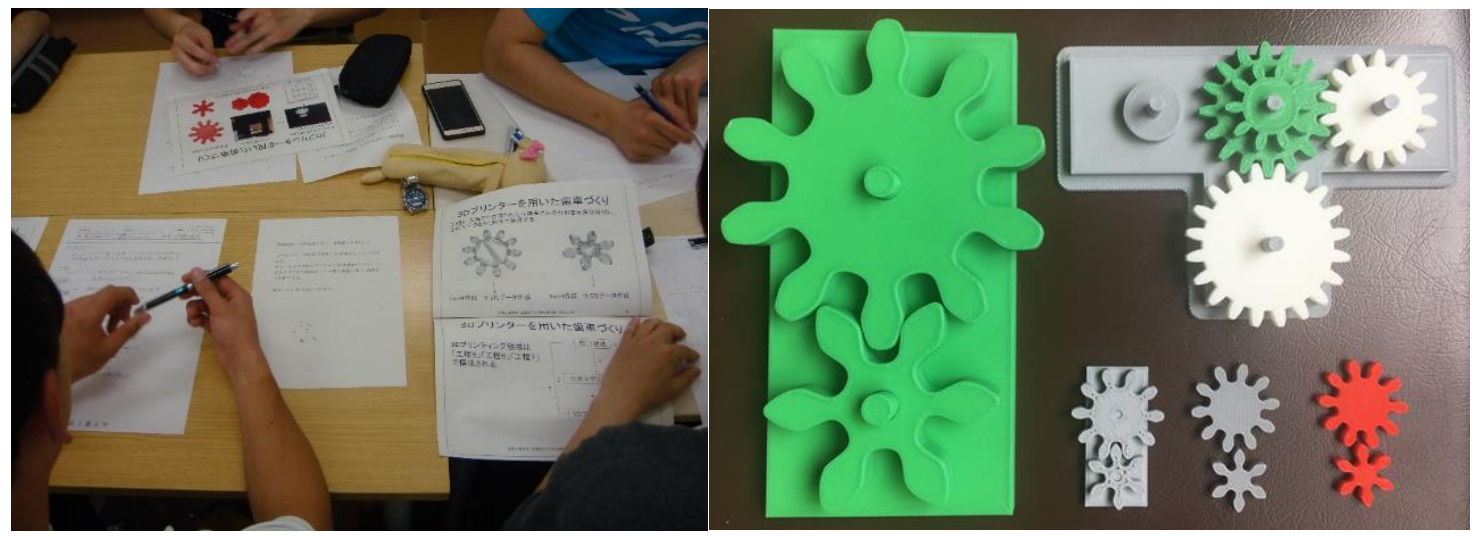

Figure 9. Pictures of students' activities and outcomes.

The students can form teams to perform the tasks underlying Figures 5-9 and keep the teamwork and leadership documentation. Finally, the students can present their work and submit a term-report, as elaborately as possible. This way, the students demonstrate their ability regarding the tertiary outcomes, that is, Outcomes $3, \ldots, 5$.

It is worth mentioning that while offering the tutorial, it can be divided into two parts. In the first part, the students are exposed to the tutorial. In this case, the course materials (Figures 5-8) can be distributed using a course content management system. The student can participate in the first half, either being at home or visiting a laboratory facility equipped with 3D printers and other relevant facilities. A report showing that they have understood the underlying processes and have built an attitude toward engineering design can be used to evaluate individual student performance. The picture shown on the left-hand side in Figure 9 shows students' activities in the first half. In the last half, the students can form teams and choose shapes (may not necessarily be a gear) and print the selected shapes following the instructions they received in the first half. A detailed presentation of the work done can be used for evaluating the performance of the teams. The picture shown on the right-hand side in Figure 9 shows some of the results of students' activities in the last half.

\subsection{Effectiveness of the Tutorial}

Apart from the outcomes assessments based on the outcomes shown in Table 1, the tutorial's effectiveness can be evaluated by studying the comments and the reports and presentation documents submitted by the students who took part in the first half and second half, respectively. Appendix A presents Table A1 listing the comments of fifteen students (from seventy-six students) who took part in the first half of the tutorial this year.

As seen in Table A1, regarding the first half of the tutorial, the students discuss various aspects of the tutorials, their expectations, and what they have learned, what they could not learn, positive aspects about 3D printing, negative aspects of 3D printing, and alike. The authors briefly describe fifteen randomly selected comments from the seventy-six students who took part in the tutorial this year. In particular, the students understood the processes underlying engineering design, CAD modeling, and 3D printing. They appreciated the role of 3D printing in materializing different shapes very quickly. They also became aware of the limitations of 3D printing (e.g., printing time, accuracy, and metallic part making). The students also extended their learning process regarding manufacturing through the tutorial. For example, some students wanted to apply 3D printing in other areas such as reverse 
engineering (rebuilding of broken objects), the materialization of natural objects (leaf-shape), and alike. They also grasped the contents they learned in other courses through the tutorial more effectively.

Regarding the second half of the tutorial, the students formed small teams and applied the knowledge they learned in the first half and performed the tasks underlying the five processes $(\mathrm{A}, \ldots, \mathrm{E})$. Each group produced a detailed presentation, including video clips and other necessary evidence showcasing their learning performances. For example, one of the gear trains shown in the picture on the right-hand side in Figure 9 was 3D printed by the students, where they used different gear-profiling equations. The students then assembled the gears and tested the backlash of the train, as prescribed in https://www.nmri.go.jp/oldpages/eng/khirata/design/ch06/ch06_02.html. This way, the students showed the accuracy of the 3D printed gears and their enhanced understanding of precision mechanisms. This kind of self-motivated learning attitude of the students can prepare them for the agile job market more effectively.

\section{Concluding Remarks}

3D-printing-relevant tutorials can prepare engineering students more effectively for their studies and careers. The contents described in this article shed light on how to educate undergraduate engineering students on the knowledge and skills of 3D printing using an outcome-oriented tutorial.

The presented tutorial development method and its implementation (3D printing of spur gears) are strictly focused on the seven ABET-prescribed outcomes. It is found that a hierarchy among the outcomes exists. Though the tutorial organizes the outcomes in three levels (primary, secondary, and tertiary), other hierarchical strategies can be considered based on the needs of an engineering program.

The tasks to be performed in the three main domains (engineering design domain, object visualization/digitization domain, and 3D printing domain) and two connecting domains (object-coordinate point cloud domain and STL data creation domain) are presented as elaborately as possible. The descriptions of the tasks help both instructors and students administer the tutorial systematically.

Based on this study's findings, an e-learning tool can be developed, ensuring online delivery.

Supplementary Materials: The following are available online at http://www.mdpi.com/2227-7102/10/8/194/s1, The supplementary material consists of a video clip showing the movements of a 3D printed gear-pinion pair.

Author Contributions: A.M.M.S.U., T., A.K., and K.H.H. conceived the idea. A.M.M.S.U. and T. conducted the literature review. A.M.M.S.U., T., and A.K. developed the method. A.M.M.S.U., T., A.K., and K.H.H. developed the course contents. A.M.M.S.U., T., and K.H.H. wrote the manuscript. A.M.M.S.U. supervised the work. All authors have read and agreed to the published version of the manuscript.

Funding: This research received no external funding.

Acknowledgments: The authors dedicate the manuscript to manufacturing educators worldwide.

Conflicts of Interest: The authors declare no conflict of interest.

\section{Appendix A. Students' Comments}

This appendix presents Table A1 listing the comments of fifteen students (from seventy-six students) who took part in the first half of the tutorial this year. 
Table A1. Students' Comments Regarding the First Half of the Tutorial.

\begin{tabular}{|c|c|}
\hline Students & Comments \\
\hline 1 & $\begin{array}{l}\text { It turns out that the gears used in many mechanical products such as cars are made through a more complicated process than I expected. I } \\
\text { thought that if there were time when } 3 \mathrm{D} \text { printers were cheap and available, it would be possible to self-repair cars and motorcycles with } \\
\text { this knowledge, especially old motorcycles. There may be cases where parts are no longer available but can be made easily by ourselves } \\
\text { using the information of the broken part. }\end{array}$ \\
\hline 2 & $\begin{array}{l}\text { This tutorial enhanced my interest in 3D printers. I had seen 3D printer only once on TV but could not grasp the technical detail until I } \\
\text { learned from this tutorial. It turned out that various parts can be made by using a 3D printer, and complex ones can be made by } \\
\text { assembling them. I think there will be more places where 3D printers will be used, so I would like to pay attention to it. }\end{array}$ \\
\hline 3 & $\begin{array}{l}\text { Though I could not use a 3D printer this time, I learned about it with great detail. I was able to learn how to handle the data of an object } \\
\text { for 3D printer. Next time, I want to use 3D printer and do by myself up to the last step to materialize a complex shape. }\end{array}$ \\
\hline 4 & $\begin{array}{l}\text { In this lecture, I learned how to make gears by using a 3D printer. I used a 3D printer before, and I find it very convenient. However, this } \\
\text { printer has the drawback of not being able to make too small parts accurately and trying to make a large one taking a great deal of time. } \\
\text { Although there are such drawbacks, it is still convenient, so I would like to continue to pay attention to 3D printers. }\end{array}$ \\
\hline 5 & $\begin{array}{l}\text { I found that designing with a 3D printer can be done with simpler procedures than I had thought. I was strongly interested in the field of } \\
\text { 3D printers that can shape what I imagined while reducing the cost of prototypes. }\end{array}$ \\
\hline 6 & $\begin{array}{l}\text { I learned about making gears using a 3D printer. I realized that there are many processes just to make gear parts and it takes time. I look } \\
\text { forward to using 3D printer to produce a part by myself using the knowledge gained in the tutorials. }\end{array}$ \\
\hline 7 & $\begin{array}{l}\text { I know about 3D printing and its utility. From this tutorial, for the first time, I could grasp the processes involved in 3D printing. It would } \\
\text { be great if I could work on a research topic related to 3D printing. }\end{array}$ \\
\hline 8 & $\begin{array}{l}\text { By learning the process of gear making using a 3D printer, I deepened my understanding and interest in manufacturing using a 3D } \\
\text { printer. I want to use the 3D printer myself. I am currently learning the usage and basics through CAD and CAE lectures, but I was able } \\
\text { to learn concretely how to make use of that knowledge, and my motivation to learn further increased. }\end{array}$ \\
\hline 9 & $\begin{array}{l}\text { This time, I could not actually experience making gears using a 3D printer due to coronavirus's influence, but I was able to understand } \\
\text { the details of the 3D printer working processes, and I felt that it was of sufficient value. I actually wanted to use a 3D printer to print } \\
\text { natural and complicated shapes (e.g., autumn leaves). }\end{array}$ \\
\hline 10 & $\begin{array}{l}\text { In this lesson, I learned how to make a 3D model using CAD and became more interested in CAD. I have not used it yet, but since I have a } \\
\text { 3D printer and I knew the manufacturing process, I wanted to make something more complicated than gears by myself. }\end{array}$ \\
\hline 11 & $\begin{array}{l}\text { 3D printing is an exciting field. There are many types of 3D printers, and I think it's exciting that you can create various three-dimensional } \\
\text { objects to suit our purposes. If we create data with CAD, we can make it by the subtractive manufacturing process. In this case, it takes } \\
\text { high skills to create the program. Nevertheless, 3D printing does not need such programming skills and makes things simple and easy. }\end{array}$ \\
\hline
\end{tabular}


Table A1. Cont.

\begin{tabular}{cl}
\hline Students & \multicolumn{1}{c}{ Comments } \\
\hline 12 & $\begin{array}{l}\text { I learned that designing mechanical parts requires a set of formulas. I knew about 3D printers from video clips posted on the Internet, but } \\
\text { this tutorial taught me the processes involved in 3D printing. Now I know the conditions and setting needed to make things using 3D } \\
\text { printing. I think that 3D printers are handy for creating small objects, but I think that it will be costly for large objects as large objects will } \\
\text { require a 3D printer larger than the objects. If 3D printers can use metal as a material and can perform complex printing, its usages will } \\
\text { expand in industrial production. }\end{array}$ \\
\hline 13 & $\begin{array}{l}\text { This time I took the course online. Next time, I want to use 3D printer by myself. Also, it was nice to know that the 3D printer not only } \\
\text { has the convenience of part making directly from 3D CAD data but also can suffer disadvantages (long printing time). }\end{array}$ \\
\hline 14 & $\begin{array}{l}\text { 3D printer will suffer limited use due to long printing time. Simultaneously, detailed knowledge of using the computing facility is needed } \\
\text { to use a 3D printer appropriately. }\end{array}$ \\
\hline It was interesting that I could get a detailed understanding of making gears using a 3D printer. I enjoyed learning about the usage of CAD \\
modeling and 3D printing in an integrated manner.
\end{tabular}




\section{References}

1. Gibson, I.; Rosen, D.; Stucker, B. Additive Manufacturing Technologies: 3D Printing, Rapid Prototyping, and Direct Digital Manufacturing, 2nd ed.; Springer: New York, NY, USA, 2015.

2. Gao, W.; Zhang, Y.; Ramanujan, D.; Ramani, K.; Chen, Y.; Williams, C.B.; Wang, C.C.L.; Shin, Y.C.; Zhang, S.; Zavattieri, P.D. The status, challenges, and future of additive manufacturing in engineering. Comput. Aided Des. 2015, 69, 65-89. [CrossRef]

3. Tofail, S.A.M.; Koumoulos, E.P.; Bandyopadhyay, A.; Bose, S.; O’Donoghue, L.; Charitidis, C. Additive manufacturing: Scientific and technological challenges, market uptake and opportunities. Mater. Today 2018, 21, 22-37. [CrossRef]

4. Balletti, C.; Ballarin, M.; Guerra, F. 3D printing: State of the art and future perspectives. J. Cult. Herit. 2017, 26, 172-182. [CrossRef]

5. Nooran, R. 3D Printing: Technology, Applications, and Selection, 1st ed.; CRC Press, Taylor \& Francis Group: Boca Raton, FL, USA, 2018.

6. ISO Standard: International Organization for Standardization (ISO)/American Society for Testing and Material (ASTM) 52900; International Organization for Standardization (ISO): West Conshohocken, PA, USA, 2015.

7. Durakovic, B. Design for additive manufacturing: Benefits, trends and challenges. Period. Eng. Nat. Sci. 2018, 6, 179-191. [CrossRef]

8. Ullah, A.M.M.S.; Kiuno, H.; Kubo, A.; D'Addona, D.M. A system for designing and 3D printing of porous structures. CIRP Ann. 2020. [CrossRef]

9. Hirz, M.; Rossbacher, P.; Gulanová, J. Future trends in CAD—from the perspective of automotive industry. Comput. Aided Des. Appl. 2017, 14, 734-741. [CrossRef]

10. Thompson, M.K.; Moroni, G.; Vaneker, T.; Fadel, G.; Campbell, R.I.; Gibson, I.; Bernard, A.; Schulz, J.; Graf, P.; Ahuja, B.; et al. Design for additive manufacturing: Trends, opportunities, considerations, and constraints. CIRP Ann. 2016, 65, 737-760. [CrossRef]

11. Yap, Y.L.; Tan, Y.S.E.; Tan, H.K.J.; Peh, Z.K.; Low, X.Y.; Yeong, W.Y.; Tan, C.S.H.; Laude, A. 3D printed bio-models for medical applications. Rapid Prototyp. J. 2017, 23, 227-235. [CrossRef]

12. 3DPrint.com. 3D Printed Clothing. Available online: https://3dprint.com/tag/3d-printed-clothing/ (accessed on 15 November 2017).

13. Balance, N. The Future of Running is Here. Available online: https://www.newbalance.com/article?id=4041 (accessed on 16 November 2017).

14. Fabian. 3D Printed Fashion: 10 Amazing 3D Printed Dresses. Available online: https://i.materialise.com/ blog/3d-printed-fashion-dresses/ (accessed on 5 May 2020).

15. Lin, C. 3D food printing: A Taste of the future. J. Food Sci. Educ. 2015, 14, 86-87. [CrossRef]

16. Hager, I.; Golonka, A.; Putanowicz, R. 3D Printing of buildings and building components as the future of sustainable construction? Procedia Eng. 2016, 151, 292-299. [CrossRef]

17. Tashi; Ullah, A.S. Symmetrical patterns of ainu heritage and their virtual and physical prototyping. Symmetry 2019, 11, 985. [CrossRef]

18. Tashi; Ullah, A.S.; Watanabe, M.; Kubo, A. Analytical point-cloud based geometric modeling for additive manufacturing and its application to cultural heritage preservation. Appl. Sci. 2018, 8, 656. [CrossRef]

19. Tashi; Ullah, A.S.; Kubo, A. Geometric modeling and 3D printing using recursively generated point cloud. Math. Comput. Appl. 2019, 24, 83. [CrossRef]

20. Minetola, P.; Iuliano, L.; Bassoli, E.; Gatto, A. Impact of additive manufacturing on engineering education-Evidence from Italy. Rapid Prototyp. J. 2015, 21, 535-555. [CrossRef]

21. Ullah, A.S.; Harib, K.H. Tutorials for integrating CAD/CAM in engineering curricula. Educ. Sci. 2018, 8, 151. [CrossRef]

22. Ford, S.; Minshall, T. Invited review article: Where and how 3D printing is used in teaching and education. Addit. Manuf. 2019, 25, 131-150. [CrossRef]

23. Chekurov, S.; Wang, M.; Salmi, M.; Partanen, J. Development, implementation, and assessment of a creative additive manufacturing design assignment: Interpreting improvements in student performance. Educ. Sci. 2020, 10, 156. [CrossRef]

24. Diriba, H.; Fraumann, G.; Maes, J. The role of higher education in 3D printing research and innovation. Work. Pap. High. Educ. Stud. 2015, 1, 62-88. 
25. Despeisse, M.; Minshall, T.S. Skills and education for additive manufacturing: A review of emerging issues. In Advances in Production Management Systems. The Path to Intelligent, Collaborative and Sustainable Manufacturing. APMS 2017. IFIP Advances in Information and Communication Technology; Lödding, H., Riedel, R., Thoben, K.D., von Cieminski, G., Kiritsis, D., Eds.; Springer: Cham, Germany, 2017; Volume 513, pp. 289-297.

26. Kirchheim, A.; Dennig, H.J.; Zumofen, L. Why education and training in the field of additive manufacturing is a necessity. In Industrializing Additive Manufacturing-Proceedings of Additive Manufacturing in Products and Applications-AMPA2017; Meboldt, M., Klahn, C., Eds.; Springer: Cham, Germany, 2018; pp. 329-336.

27. Urbanic, R.J. From thought to thing: Using the fused deposition modeling and 3D printing processes for undergraduate design projects. Comput. Aided Des. Appl. 2016, 13, 768-785. [CrossRef]

28. Fidan, I.; Chitiyo, G.; Singer, T.; Moradmand, J. Additive manufacturing studios: A new way of teaching ABET student outcomes and continuous improvement. In Proceedings of the 2018 ASEE Annual Conference \& Exposition, Salt Lake, UT, USA, 24-28 June 2018. Paper ID: \#22068.

29. Ali, N.; Khine, M.S. Integrating 3D Printing into Teaching and Learning; Brill Sense: Leiden, The Netherlands, 2020.

30. Alhamad, I.M.; Ahmed, W.K.; Ali, H.Z.; AlJassmi, H. 3D printing applications in mechanical engineering education. In Integrating 3D Printing into Teaching and Learning; Brill Sense: Leiden, The Netherlands, 2019; pp. 90-113.

31. Asiabanpour, B. Additive manufacturing: Instrumental systems used in research, education, and service. In Additive Manufacturing—Developments in Training and Education; Pei, E., Monzón, M., Bernard, A., Eds.; Springer International Publishing: Cham, Switzerland, 2019; pp. 35-52.

32. Lin, K.Y.; Hsiao, H.S.; Chang, Y.S.; Chien, Y.H.; Wu, Y.T. The effectiveness of using 3D printing technology in STEM project-based learning activities. Eurasia J. Math. Sci. Technol. Educ. 2018, 14, em1633. [CrossRef]

33. Loy, J. ELearning and eMaking: 3D printing blurring the digital and the physical. Educ. Sci. 2014, 4, 108-121. [CrossRef]

34. Galina, L.; Na, X. Academic library innovation through 3D printing services. Libr. Manag. 2017, 38, $208-218$. [CrossRef]

35. Heather, M.M.L. Makers in the library: Case studies of 3D printers and maker spaces in library settings. Libr. Hi Tech. 2014, 32, 583-593. [CrossRef]

36. Verner, I.; Merksamer, A. Digital design and 3D printing in technology teacher education. Procedia CIRP 2015, 36, 182-186. [CrossRef]

37. Liu, H.; Jin, X. Digital manufacturing course framework for senior aircraft manufacturing engineering undergraduates. Comput. Appl. Eng. Educ. 2020, 28, 338-356. [CrossRef]

38. Ransikabum, K.; Yingviwatanapong, C.; Leksomboon, R.; Wajanavisit, T.; Bijaphala, N. Additive manufacturing-based healthcare 3D model for education: Literature review and a feasibility study. In Proceedings of the 2019 Research, Invention, and Innovation Congress (RI2C), Bangkok, Thailand, 11-13 December 2019; pp. 1-6.

39. Li, K.H.C.; Kui, C.; Lee, E.K.M. The role of 3D printing in anatomy education and surgical training: A narrative review. MedEdPublish 2017, 6. [CrossRef]

40. Abouhashem, Y.; Dayal, M.; Savanah, S.; Štrkalj, G. The application of 3D printing in anatomy education. Med. Educ. Online 2015, 20, 29847. [CrossRef]

41. Smith, C.F.; Tollemache, N.; Covill, D.; Johnston, M. Take away body parts! An investigation into the use of 3D-printed anatomical models in undergraduate anatomy education. Anat. Sci. Educ. 2018, 11, 44-53. [CrossRef]

42. Cai, B.; Rajendran, K.; Bay, B.H.; Lee, J.; Yen, C.-C. The effects of a functional three-dimensional (3d) printed knee joint simulator in improving anatomical spatial knowledge. Anat. Sci. Educ. 2019, 12, 610-618. [CrossRef]

43. Jones, D.G. Three-dimensional printing in anatomy education: Assessing potential ethical dimensions. Anat. Sci. Educ. 2019, 12, 435-443. [CrossRef]

44. Young, J.C.; Quayle, M.R.; Adams, J.W.; Bertram, J.F.; McMenamin, P.G. Three-Dimensional printing of archived human fetal material for teaching purposes. Anat. Sci. Educ. 2019, 12, 90-96. [CrossRef]

45. Buehler, E.; Comrie, N.; Hofmann, M.; McDonald, S.; Hurst, A. Investigating the implications of 3D printing in special education. ACM Trans. Access. Comput. 2016, 8, 1-28. [CrossRef] 
46. Engineering, N.A.O. Forum on Proposed Revisions to ABET Engineering Accreditation Commission General Criteria on Student Outcomes and Curriculum (Criteria 3 and 5): A Workshop Summary; The National Academies Press: Washington, DC, USA, 2016. [CrossRef]

47. National Academy of Engineering. Engineering Societies and Undergraduate Engineering Education: Proceedings of a Workshop; The National Academies Press: Washington, DC, USA, 2017. [CrossRef]

48. ABET. Criteria for Accrediting Engineering Programs, 2020-2021. Available online: https://www.abet.org/ accreditation/accreditation-criteria/criteria-for-accrediting-engineering-programs-2019--2020/ (accessed on 16 April 2020).

49. ISO Standard: Standard Specification for Additive Manufacturing File Format (AMF) Version 1.1. Available online: https://www.iso.org/standard/61944.html (accessed on 15 November 2017).

50. Ullah, A.S. Fundamental issues of concept mapping relevant to discipline-based education: A perspective of manufacturing engineering. Educ. Sci. 2019, 9, 228. [CrossRef]

51. Kinchin, I.M.; Möllits, A.; Reiska, P. Uncovering types of knowledge in concept maps. Educ. Sci. 2019, 9, 131. [CrossRef]

52. Mott, R.L.; Vavrek, E.M.; Wang, J. Machine Elements in Mechanical Design, 6th ed.; Pearson: New York, NY, USA, 2018.

53. Anand, V.B. Computer Graphics and Geometric Modeling for Engineers; Wiley: New York, NY, USA, 1993.

54. Ullah, A.M.M.S.; D'Addona, D.M.; Harib, K.H.; Lin, T. Fractals and additive manufacturing. Int. J. Autom. Technol. 2016, 10, 222-230. [CrossRef]

55. Ullah, A.M.M.S.; Hashimoto, H.; Kubo, A.; Tamaki, J. Sustainability analysis of rapid prototyping: Material/resource and process perspectives. Int. J. Sustain. Manuf. 2013, 3, 20-36. [CrossRef]

(C) 2020 by the authors. Licensee MDPI, Basel, Switzerland. This article is an open access article distributed under the terms and conditions of the Creative Commons Attribution (CC BY) license (http://creativecommons.org/licenses/by/4.0/). 